\title{
"You're Totally on Your Own": Experiences of Food Allergy on a Canadian University Campus
}

\author{
Alexandra S. Olarnyk ${ }^{1, *}$, Susan J. Elliott ${ }^{2}$ \\ ${ }^{1}$ Centre for Knowledge Integration, University of Waterloo, Canada \\ ${ }^{2}$ Geography and Environmental Management \& School of Public Health and Health Systems, University of Waterloo, Canada
}

Copyright $(\mathcal{C} 2016$ by authors, all rights reserved. Authors agree that this article remains permanently open access under the terms of the Creative Commons Attribution License 4.0 International License

\begin{abstract}
With the prevalence of food allergies within Canada estimated at approximately $7 \%$, researchers have sought a variety of perspectives to inform our understanding of food allergy risk and perception (Soller et al., 2012). However, university students' perception of food allergies is an area of little research that needs prompt attention in light of a recent death (2015), due to anaphylactic shock, of an 18-year old Canadian university student (Vuchnich, 2015b). Since the perception that the prevalence of food allergies is increasing, investigation into the risks involved when transitioning into university with a food allergy are needed (Harrington et al., 2012). This study explores the experiences and perceptions of food allergic undergraduate students of the University of Waterloo, Canada. The two main objectives include: (1) to understand how food allergic university students experience and perceive food allergy risk on campus; and (2) to understand their management and coping strategies. Five focus groups were conducted with a total of twenty participants. Focus groups were audio-recorded and transcribed verbatim for subsequent thematic analysis. Results are organized into three themes: perceptions and experiences, coping and management, and changes and improvements. The key findings indicate that participants are experiencing difficult transitions into university and social isolation as a result of their food allergy, which has caused them to engage in risk-taking behaviours. This sets the stage for serious policy implications that the university should undertake in order to create a context that is inclusive for students with food allergies.
\end{abstract}

Keywords Food Allergy, University Student, Anaphylaxis, Vulnerability, Social Isolation, Risk-taking, Coping, Perception

\section{Introduction}

“Queen's student Andrea Mariano died Friday after suffering a severe anaphylactic attack from a smoothie she bought on campus"[1]

The tragic death of an 18-year-old Queen's University student emphasizes the need for action to prevent any further food allergy related fatalities on university campuses. Action has already occurred with many Canadian universities responding quickly to the news by reviewing their own policies on food allergies [2]. However, there is currently no consistent policy framework for food allergies across Canadian universities, and in order to create effective policies, the perspectives of food allergic university students must be acknowledged.

With approximately 2.5 million Canadians estimated to have a food allergy, researchers have sought the perspectives of a variety of individuals to inform our understanding of food allergy perception and risk. However, university students' experiences and perceptions on food allergies is an area of little research. The existing literature hosts only two other studies that have examined food allergy on university campuses [3,4]. Greenhawt[3] was the first, identifying food allergic university students to have a general sense of invulnerability and poor perception of their health care needs due to less than optimal notification methods, medication ownership, and avoidance of a food allergen.

The perspectives of food allergic university students are important to continue to study because these students are a vulnerable population. Full responsibility to manage allergen risk is transferred to the student once they leave home and begin university; they must have a heightened awareness of their environment and its new or non-existing policies for food allergy risk management, exercise caution in their eating decisions, and participate in risk-reducing behaviours. However, when compared to other age groups, young adults have also been proven to be at the highest risk for fatal food-induced allergic reactions due to risk-taking behaviours when managing their food allergies [5-7]. To emphasize this point, the Queen's student was not carrying any of her auto-injectors when her anaphylactic reaction occurred [1]. Risk-taking behaviours can also be implemented as an attempt to reduce the experience of social isolation, which is commonly caused by avoidance strategies associated with 
having a food allergy [7].

The combination of increased vulnerability and higher likelihood of risk-taking behaviours, particularly caused by feelings of social isolation, is of concern because it may put university students at an even greater risk for an allergic reaction. This emphasizes the need to need to continue to explore the intersection between food allergy and university students' perspectives in order to address unmet needs and improve the experiences of food allergic students on campus. Therefore, the objectives of this study were to: (1) understand how food allergic university students perceive and experience food allergy risk on campus; and (2) understand the management and coping strategies of food allergic university students when making decisions to eat on campus.

\section{Materials and Methods}

Five focus groups were conducted with 20 food allergic undergraduate students of the University of Waterloo, Canada. Focus groups were the chosen methodology because their exploratory nature is particularly useful as means of initial inquiry into new areas of investigation [8]. They also carry the strengths of being a qualitative research method. First, focus groups provide context and depth by encouraging a dialogue that shares and compares experiences, allowing each participant to build upon their responses towards a more considered and in-depth level $[9,10]$. Second, the method allows for interpretation; providing an understanding as to why diversity or similarity occurs amongst the range of participant experiences [10].

Ethics approval was received from the university's board of research ethics prior to recruitment. A purposeful sampling strategy of snowball sampling and maximum variation was used [11]. Maximum variation among the type of food allergy, severity of food allergy, sex, age, country of birth, degree of study, term of degree, faculty, co-operative educational status, housing status, and student status were implemented. Recruitment flyers were posted within all faculty buildings, residence areas, and the university's health centre.

Interested participants were screened for: 1) type of food allergy, 2) who diagnosed them, and 3) how they were diagnosed. Participants included in the study were those who stated they were diagnosed by a family physician or allergist and who had a positive skin test, an IgE level blood test or a positive food challenge. Common characteristics among participants were: 1) having a self-identified food allergy, 2) current undergraduate student at the university, 3) 18+ years of age, and 4) fluent in English.

Data collection occurred over a one-month period in March 2015. Each focus group began by participants filling out a demographic questionnaire, followed by the discussion portion. Topics discussed included perceptions and experiences, management strategies, and desired changes and improvements of food allergy management on campus.
All participants gave ethical approval via written consent prior to the focus group. The honorarium of a $\$ 5$ gift card was provided to all participants.

All focus groups were conducted by the same researcher and were digitally recorded and transcribed verbatim for subsequent thematic analysis via hand- coding using editing and template style [8]. Pseudonyms were used to keep participant quotations anonymous and protect the identity of the participants. Deductive reasoning was used to identify themes related to research objectives and the discussion topic guide, while inductive reasoning was used to identify themes arising from the transcripts [8]. Additionally, each focus group was treated as the unit of analysis, which allowed within-group and across-group similarities and differences to be assessed [8].

\section{Results}

\subsection{Participant Characteristics}

Table 1. Participant Characteristics $(n=20)$

\begin{tabular}{|c|c|c|}
\hline Characteristic & $\begin{array}{l}\text { Number of } \\
\text { Participants }\end{array}$ & $\begin{array}{c}\text { Percent of } \\
\text { Participants }\end{array}$ \\
\hline \multicolumn{3}{|l|}{ Sex } \\
\hline Male & 8 & $40 \%$ \\
\hline Female & 12 & $60 \%$ \\
\hline \multicolumn{3}{|l|}{ Age } \\
\hline $18-21$ & 17 & $85 \%$ \\
\hline $22-25$ & 3 & $15 \%$ \\
\hline \multicolumn{3}{|l|}{ Faculty } \\
\hline Arts & 7 & $35 \%$ \\
\hline Engineering & 4 & $20 \%$ \\
\hline Environment & 5 & $25 \%$ \\
\hline Math & 1 & $5 \%$ \\
\hline Science & 1 & $5 \%$ \\
\hline Applied Health Sciences & 2 & $10 \%$ \\
\hline \multicolumn{3}{|l|}{ Current Year of Degree } \\
\hline 1 & 8 & $40 \%$ \\
\hline 2 & 1 & $5 \%$ \\
\hline 3 & 5 & $25 \%$ \\
\hline 4 & 5 & $25 \%$ \\
\hline $5+$ & 1 & $5 \%$ \\
\hline \multicolumn{3}{|l|}{ Enrollment Status } \\
\hline Full-time & 20 & $100 \%$ \\
\hline \multicolumn{3}{|l|}{ Housing Status } \\
\hline On campus & 8 & $40 \%$ \\
\hline Off campus & 12 & $60 \%$ \\
\hline \multicolumn{3}{|l|}{$\begin{array}{c}\text { Owns Allergy Medication } \\
\text { (SIE, Benadryl® or } \\
\left.\text { Reactine }{ }^{\circledR}\right) \\
\end{array}$} \\
\hline Yes & 17 & $85 \%$ \\
\hline No & 3 & $15 \%$ \\
\hline
\end{tabular}

Table 1 accounts for the participants with multiple allergies 


\subsection{Food Allergies Reported}

The most common food allergies reported were to peanuts, tree nuts, or seafood, as displayed in Figure 1. All anaphylactic participants owned a SIE device that could be used for an allergic reaction $(n=17)$. Of the participants who did not own any allergy medication $(n=3)$, all had moderately severe allergies to either shellfish $(n=1)$ or caffeine $(n=1)$, or had been recently diagnosed within the past year $(n=1)$.

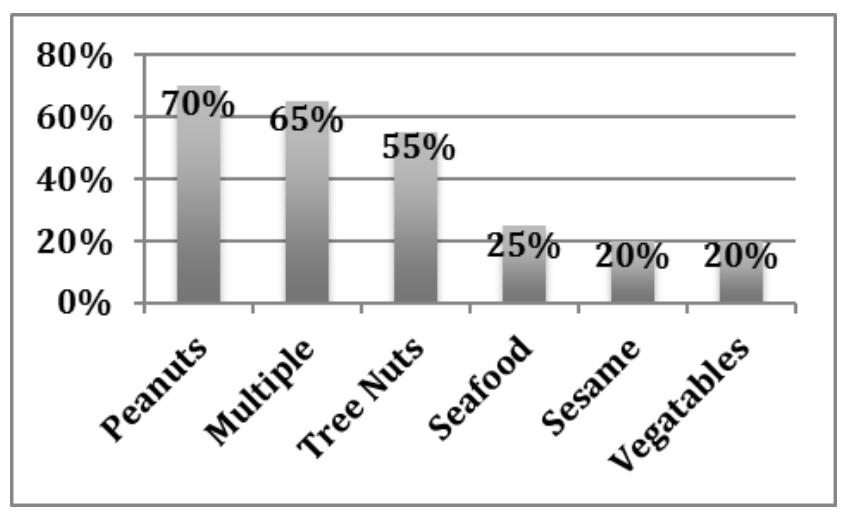

Figure 1. Top food allergies amoung participants

\subsection{Three Main Themes}

Three main themes emerged from the five focus groups: perceptions and experiences, coping and management, and changes and improvements.

\subsubsection{Perceptions and Experiences}

\subsubsection{Reactions on Campus}

$25 \%$ of the participants suffered an allergic reaction on campus $(n=5) .40 \%$ of participants had an anaphylactic reaction $(n=2)$, while $60 \%$ had a moderate reaction $(n=3)$. The majority occurred in their first month of being a student and were triggered by food from a residence cafeteria $(n=3)$. Reactions impacted participants' daily life, including their ability to attend lectures or to stay focused while doing homework. One participant described her experience feeling sick through class due to painful stomach cramps caused by an allergic reaction:

"I have eaten something and gotten sick and it has just been frustrating because I planned to stay on campus and now I feel sick through class... for a couple of hours. My stomach gets really bad cramps, which impacts the focus on my day and doing things. If it is really bad I just go home and curl up into a ball." (Amy-Female-Moderate allergy to wheat, beef, chicken, peanuts, corn, shrimp, egg, cow's dairy)

Some even had concerning priorities, placing schoolwork above treating an allergic reaction, as one participant describes:

"I went back to my room because my throat was sore, and I didn't want to take Benadryl because I had a midterm that night and didn't want to be tired..." (Rachelle-Female-Anaphylactic to peanuts and tree nuts)

\subsubsection{Transition into University}

Half of the participants commented about their experience transitioning from high school into university with a food allergy. The minority of these participants felt indifferent about their transition $(n=4)$, while the majority experienced the transition as difficult; paranoia and stress were commonly expressed feelings $(n=6)$. Some of the participants who experienced a difficult transition described university as an environment with fewer precautions and less involvement from staff in helping to manage food allergies compared to elementary and high school $(n=2)$ :

"One thing I find surprising is in primary school they take so many precautions... and then in high school they sort of don't care and then in university there is just no care at all, you're totally on your own."(Micha-Female-Anaphylactic to peanuts and tree nuts)

"I didn't expect it [the transition] to be so hard because in high school it's a closed environment, peanuts aren't really allowed and then I came here [university] and in class people can eat whatever they want and I found myself very weary of what I was touching ... and it got me into a paranoia for a while, but I am getting over it slowly."(Ruth-Female-Anaphylactic to peanuts, tree nuts and sesame)

Others described the lack of support or protection available from their parents $(\mathrm{n}=2)$ :

"I always had my mom's second opinion on the judgment on whether I should eat something, whereas here I am completely on my own to make up my own mind about risk." (Rhina-Female-Anaphylactic to peanuts, tree nuts and fish)

$15 \%$ of participants said their allergy became less of a concern or priority after transitioning into university $(n=3)$. Schoolwork and friends took priority:

"In university ... you are focused on your studies and friends and integrating into this new environment and you are rushing around, so the allergy becomes less important." (Cathy-Female-Anaphylactic to peanuts)

\subsubsection{Feeling Left out}

$35 \%$ of participants described a situation where they could not eat the communal food $(n=7)$, causing them to miss out on a university event. One participant experienced this within her first year:

"Every Friday night was pizza night and my dairy allergy would prevent me from eating pizza and my 
meal plan doesn't allow me to eat at other residence cafeterias ... So I just bought hummus and pitas and ate in my room alone while everyone else was having pizza."(Faitsha-Female-Anaphylactic to tree nuts, eggs and dairy)

The same participant later stated that she would risk giving herself small allergic reactions in order to feel included in routine with those around her:

“... once I started being able to have small amounts of dairy again I pushed it, giving myself small reactions. I take a lot of risks because I want to be able to participate." (Faitsha-Female-Anaphylactic to tree nuts, eggs and dairy)

\subsubsection{Feeling like a Burden}

$25 \%$ of participants felt as if they were being a burden when asking others to accommodate their allergy $(n=5)$. They felt "bad", or "guilty" because they were "putting others out" or being "an onus".

"Sometimes I wonder that my allergy is a bit of a downer on some people, ... it always prevents people from having peanut butter in the cafeteria. It almost makes me want to not advertise my allergy so I don't get looked down upon." (Adam-Male-Anaphylactic to peanuts and moderate allergy to tree nuts)

\subsubsection{Coping and Management}

The most common strategy to manage allergen risk was to have a "look out for yourself" attitude $(\mathrm{n}=5)$. This attitude is required since they have to deal with less staff and students who recognize them for their allergy compared to elementary and high school $(\mathrm{n}=3)$. They also have to deal with university environments where people can "bring in all types of food" or are "uneducated" about what common allergens may be present. Such an environment made one participant feel restricted to sitting in the back of the classroom:

"I was in lecture once and someone was eating a peanut butter sandwich next to me and ... my throat felt funny and I left class ... after that I would try to sit beside my friends who knew about my allergy and at the back of classes so I can just be aware of my surroundings." (Ruth-Female-Anaphylactic to peanuts, tree nuts and sesame)

Two types of environments were found to be the most challenging. First, busy environments were challenging for $25 \%$ of participants since they found that these types of environments make it difficult to ask for accommodation $(\mathrm{n}=5)$. Second, large-scale university environments such as lecture halls and events were challenging for $15 \%$ of participants when the food allowed into the environment contained an allergen $(n=3)$. They described this type of environment as having high risk for cross-contamination on common surface areas and as being challenging to have one's voice heard when expressing concern for such risks.
"I was in [residence name] and they were having tons of Nutella treats for National Nutella day and I was like wow that's really scary because clearly it's a common allergy and they're just throwing all these nuts around." (Audrena-Female-Anaphylactic to tree nuts and peanuts)

\subsubsection{Changes and Improvements}

Participants were asked whether they would like to see any changes or improvements as to how food allergies are managed on campus. Three themes emerged. First, some participants expressed the desire to be told what they can have instead of what they cannot have $(\mathrm{n}=2)$, turning a negative restriction into a positive inclusion. Second, it was evident that participants did not want the task of asking food service staff about allergens made into a "big deal" $(\mathrm{n}=4)$ :

"The times I asked in the [university cafeteria] if something had nuts, they wouldn't know... and then just end up bringing me the box so I can read it myself... so I'm standing there with this stupid big box reading the ingredients because they have no idea." (Audrena-Female-Anaphylactic to tree nuts and peanuts)

Third, participants would like to see patient dining staff that can recognize allergic individuals, anticipate common allergy questions, and feel confident when providing answers $(\mathrm{n}=12)$.

\section{Discussion}

With food allergies becoming a newly emerging health risk and as new generations of food allergic individuals enter into university, the topic of creating an on-campus context that is safe for such individuals is becoming a pressing matter. The fatal anaphylactic reaction of the Queen's university student has pressured many Canadian universities to reflect and improve upon their own policies regarding food allergies [2]. In order to effectively improve or create such policies, understanding the experiences and perceptions of food allergic university students is a strong starting point that can provide relevance for policy interventions.

The key findings highlight how one Canadian university, the University of Waterloo, has not yet constructed a social context that is inclusive for students with food allergies. This is of concern because food allergic university students are a vulnerable population, as they no longer have their parents, peers, or familiar school policy contexts to assist them in managing their allergy.

In terms of perceptions and experiences, the transition into university with a food allergy can be difficult. Compared to elementary and high school, half of the participants experienced that university faculty and staff take fewer precautions and less involvement in the management of food allergies. Participants also lacked the second opinion about allergen risk once regularly provided by their parents, as well 
as the recognition for having an allergy from their peers. These challenges emphasize how some participants felt completely on their own to manage their allergy once leaving home to attend university.

It is not new to published research that food allergic children, adolescents and young adults can feel socially isolated because of their allergy $[7,13,14]$. However, feelings of social isolation due to having a food allergy have not yet been recorded within a university student population. Within this study it was evident that food allergic students experienced feeling socially isolated due to their food allergy. Over a third of participants described university events or lecture halls that lacked the consideration for students with food allergies, causing them to feel like the odd one out. These feelings of isolation led some participants to choose not to attend such events, or to feel restricted to sitting only in certain areas of a classroom, specifically the back, in order to feel safe. Even more concerning, to avoid feelings of social isolation some participants engaged in risk-taking behaviours by prioritizing school concerns over health concerns. This would occur by participants either giving themselves small allergic reactions in order to feel included or choosing to still attend classes and struggle through painful symptoms after having experienced an allergic reaction. One participant even decided not to take medication in the event of an allergic reaction since she had an upcoming midterm she feared missing, regardless of experiencing an itchy throat and knowing she was anaphylactic. These findings suggest that food allergic university students might mentally and physically push themselves to an unhealthy or even fatal limit in order to conform more to the same experiences of non-food allergic students and avoid feeling isolated.

Other risk-taking behaviours found within this study align with the Greenhawt[3] study exploring food allergic university students' experiences with food allergy at a U.S. university. Both studies identify the willingness of food allergic university students to eat foods known to contain an allergen. Second, both studies find that students choose not to mention their allergy to food service staff. The third risk-taking behavior is the habit of anaphylactic individuals not always carrying their SIE.

In terms of coping and management, one quarter of participants adopted a "look out for yourself" attitude as their main strategy for managing allergen risk. For example, they would feel full responsibility to make sure that their allergy was properly communicated to friends and/or food service staff. For some, this was viewed as necessary since they no longer had their parents available to advocate for their allergy. However, independently controlling allergen risk is not always an easy task as students have only so much capacity to ask others to accommodate their allergy, especially in lecture halls of up to 500 students.

Given our findings, we see evidence that some of the current practices at the university create a context that causes feelings of social isolation for its food allergic students. Furthermore, the University of Waterloo currently has released no public information on their policies regarding food allergies. Without such a policy, uninformed food allergy practices might exist, and an environment is created where feelings of isolation for food allergic students can persist. In order to reduce these feelings and negative experiences, several recommendations are made that can be used to direct policy regarding food allergy management on campus. First, food allergic students would like the university to make efforts towards highlighting their options instead of restrictions; allowing them to feel integrated into the environment rather than separated by statements of avoidance. Second, students do not want the task of asking about food allergens to be made into a "big deal" by food service staff. Staff should make the task of asking for accommodation feel simple and avoid it being turned into a scenario that isolates the allergic individual who placed the inquiry. Third, students want to see improvements to the knowledge and demeanor of food service staff. If staff had the confidence to anticipate common allergy questions, then food allergic individuals would feel included. In general, staff should be proactive to make food allergy consideration a part of their daily routine. These policies should particularly be directed toward dining halls since they are a common area for allergic reactions since many university students primarily depend on university dining services for their meals [15]. To exemplify this point, three out of five of the participants' reactions on campus within this study were triggered by food from a residence dining hall. In addition, an article within Allergic Living magazine revealed that $25 \%$ of all dining areas within sixteen Canadian universities had a student suffer an anaphylactic reaction in the past 4 years [16].

This was the first study to use focus groups as the methodological technique for exploring food allergies on a university campus. Of the two other studies that have examined food allergy on university campuses, both used surveys as their methodological technique $[3,4]$. Focus groups are beneficial because they give a voice to vulnerable populations [17]. They also allowed for the flexibility to explore this new area of inquiry in ways that a survey cannot $[8,17]$. Participants mentioned that they enjoyed the focus group method as an opportunity to share stories of experience and advice on coping and management with other like individuals, making them feel less socially isolated despite having an allergy on campus. This speaks to the importance of reducing feelings of social isolation.

Two major limitations were that this study was restricted to one university and had a sample size of twenty participants. This is consistent with a qualitative research design. However, further research could and should focus on a comparative analysis across different university campuses to determine whether the experiences found within this study would emerge within a broader, larger sample. Data should be collated until the point of saturation is reached, i.e. no new insights are being generated by the data collection. This is important because universities have differing policies and practices regarding food allergy management, which will 
mean differing student experiences and perceptions. Furthermore, when investigating new areas of inquiry, focus groups are often used as a source of preliminary data to influence subsequent quantitative research, particularly the design of questionnaires and other survey instruments [18]. This is because focus groups provide a means to understand what topics are most relevant to potential respondents and how they think about the phenomenon of interest [18]. Therefore, this study's very rich exploratory qualitative data could and should be used to inform the design of a large-scale quantitative survey of university campuses across North America in order to address this growing public health epidemic.

\section{Conclusions}

In light of the tragic death of the Queen's university student, and as new generations of food allergic individuals continue to enter into university, there will be a need to recognize the varied experiences of food allergy amongst students in order to direct effective food allergy policy. The findings of this study indicate that the University of Waterloo has not yet created a context that is inclusive for students with food allergies, which has caused them to engage in risk-taking behaviours and adopt "look out for yourself" attitudes. Further research is needed in order to determine if the experiences found within this study differ within a broader sample across various university campuses. Implications for this research can be targeted towards improving or creating university policy on food allergy. It is important for universities to anticipate and become aware of environments that could socially isolate students with food allergies. Once awareness has been made, efforts can be directed towards creating more inclusive environments for current and incoming students with a food allergy. This would assist in making the transition into university easier and reduce the amount of vulnerability for such students.

\section{Acknowledgements}

I would like to thank Susan Elliott and the rest of the GoHelp lab members at the University of Waterloo for providing a community of support for my research.

\section{REFERENCES}

[1] Vuchnich, A. Canadian student dies after ordering smoothie on campus; suffers severe allergic reaction: family. Global News, 2015. Online available from: http://globalnews.ca/news/2232790/canadian-student-dies-af ter-ordering-smoothie-on-campus-suffers-severe-allergic-rea ction-family/. Accessed September 23, 2015.

[2] Vuchnich, A. Multiple Canadian universities reviewing policies after student dies from allergic reaction. Global News,
2015. Online available from: http:/globalnews.ca/news/2234905/multiple-canadian-unive rsities-reviewing-policies-after-student-dies-from-allergic-re action/. Accessed September 24, 2015.

[3] Greenhawt, M. J., Singer, A. M., \& Baptist, A. P. Food allergy and food allergy attitudes among college students. $J$ Allergy Clin Immunol, 124(2), 323-327, 2009. http://doi.org/10.1016/j.jaci.2009.05.028

[4] French, D., \& Pobocik, R. S. Food Allergies in University Dining: An Assessment to Meet the Needs of Food Allergic Students. J Nutr Educ Behav, 45(4, Supplement), S31, 2013. http://doi.org/10.1016/j.jneb.2013.04.085

[5] Bock, S. A., Muñoz-Furlong, A., \& Sampson, H. A. Fatalities due to anaphylactic reactions to foods. J Allergy Clin Immunol, 107(1), 191-193, 2001. http://doi.org/10.1067/mai.2001.112031

[6] Sampson, M. A., Munoz-Furlong, A., \& Sicherer, S. H. Risk-taking and coping strategies of adolescents and young adults with food allergy. J Allergy Clin Immunol, 117(6), 1440-1445, 2006.

[7] Peniamina, R. L., Bremer, P., Conner, T. S., \& Mirosa, M. Understanding the Needs of Food-Allergic Adults. Qual Health Res, 24(7), 933-945, 2014. http://doi.org/10.1177/1049732314539733

[8] Crabtree, B. F., \& Miller, W. L. Doing Qualitative Research, 2nd ed., Sage Publications, Inc, United States, 1999.

[9] Ritchie, J., Lewis, J., Lewis, P. of S. P. J., Nicholls, C. M., \& Ormston, R. Qualitative Research Practice: A Guide for Social Science Students and Researchers, 2nd ed., Sage Publications, Inc, United States, 2013.

[10] Morgan, D. L. The Focus Group Guidbook: Kit 1, 1st ed., Sage Publications, Inc, United States, 1997

[11] Babbie, E. R. Fundamentals of social research, 3rd Canadian ed., Nelson Education, Canada, 2014.

[12] Brown, J., B. The Use of Focus Groups in Clinical Research. In Doing Qualitative Research, 2nd ed., Sage Publications, Inc, United States, pp. 109-127, 1999.

[13] Fenton, N. E., Elliott, S. J., Cicutto, L., Clarke, A. E., Harada, L., \& McPhee, E. Illustrating Risk: Anaphylaxis Through the Eyes of the Food - Allergic Child. Risk Anal. 31(1), 171-183, 2011. doi: 10.1111/j.1539-6924.2010.01488.x

[14] MacKenzie, H. Teenagers' experiences of living with food hypersensitivity: A qualitative study. Pediatr Allergy Immunol, 21(4p1), 595-602, 2010.

[15] Gavorek, C. L., \& Mistry, A. M. Making Accommodations for Students with Food Allergies and Special Diets in a Campus Setting. J Acad Nutr Diet, 114(9, Supplement), A30, 2014. http://doi.org/10.1016/j.jand.2014.06.092

[16] French, J. Off to Canadian University with Allergies, Celiac Allergic Living. Retrieved December 1, 2014, from: http://allergicliving.com/2014/08/06/off-to-college-with-aller gies-celiac-canada/

[17] Morgan, D. L. Focus Groups. In Approaches to Qualitative Research: A Reader on Theory and Practice, Oxford University Press, Inc, pp. 263-281, 2004.

[18] Stewart, D. W. Focus Groups: Theory and Practice, Sage 
Publications, Inc, United States, 1990.

[19] Harrington, D. W., Elliott, S. J., \& Clarke, A. E. Frames, claims and audiences: Construction of food allergies in the Canadian media. Public Underst Sci, 21(6), 724-739, 2012. http://doiorg/ 10.1177/0963662510393083.
[20] Soller, L., Ben-Shoshan, M., Harrington, D. W., Fragapane, J., Joseph, L., St. Pierre, Y., ... Clarke, A. E. Overall prevalence of self-reported food allergy in Canada. J Allergy Clin Immunol, 130(4), 986-988, 2012. http://doi.org/10.1016/j.jaci.2012.06.029 